\title{
Bond-shear Behavior of FRP Rods as a Function of Attachment Configuration
}

\author{
Agung Budipriyanto ${ }^{1}$, Ay Lie $\mathrm{Han}^{2 *}$ and Hsuan-Teh $\mathrm{Hu}^{3}$ \\ ${ }^{I}$ Associate Professor, Department of Civil Infrastructure Engineering, Institut Teknologi Sepuluh Nopember, \\ Kampus ITS Manyar, Surabaya 60116, Indonesia \\ ${ }^{2}$ Professor, Department of Civil Engineering, Faculty of Engineering, Diponegoro University \\ Jalan Prof. H. Soedarto S.H., Tembalang, Semarang 50275, Indonesia \\ ${ }^{3}$ Professor, Civil Engineering Department, National Cheng Kung University, \\ 1 University Road, Tainan City, Taiwan (ROC) \\ *Corresponding author:hanaylie@live.undip.ac.id
}

(Received: March $4^{\text {th }}, 2018$; Accepted: March 13 $\left.{ }^{\text {th }}, 2018\right)$

\begin{abstract}
The use of external reinforcement to improve or enhances the flexural capacity of a member depends on the transfer capacity, and the failure behavior of the composite between the reinforcement, the epoxy resin and the concrete. The most influencing factor is the bond-shear capacity between the rod and the epoxy, and the epoxy to the concrete. Fiber Reinforced Polymer (FRP) rods are the latest alternate for fulfilling the external reinforcement scheme. In the field, the mandated embedment depth as outlined by the ACI 440 code, could customary not be achieved since factors such as the depth of the concrete cover, and presence of stirrups limits the space. This study is aimed to evaluate the effect of FRP rod configurations with respect to the concrete surface, to the effectiveness of external reinforcement. The study looked into the bond-shear capacity as well as the mode of failure, influence by the rod attachment depth. It was shown that the embedment depth significantly influenced the failure mode, and therefore the strain transfer capacity from the concrete to the rods.
\end{abstract}

Keywords: bond-shear, FRP rods, embedment depth, mode of failure

\section{INTRODUCTION}

Reinforced concrete flexural members depend highly on the transfer of tensile strains in the flexural tension area, to the reinforcement. Since concrete from its nature is very weak in tension, the reinforcing steel situated in these tensile zones are crucial in determining the capacity and ductility performance of a member in bending. Conventional steel bars are customarily situated within the section, and the tensile strain from the concrete to these reinforcing steel members is transferred through the bond between the steel bars and the concrete. A significant concrete cover in combination with densely compacted concrete in the steel vicinity will guaranty the compatibility of the member under monotonic, as well as cyclic loading.

In certain situations, such as alteration of building codes, or enhancement in load carrying capacity requirements due to an increase in users demands, it will become necessary to reinforce flexural members externally. This method is not only time effective, but from the economical point of view, this option always presents a better solution then demolishing and re-construction the members. External reinforcements provided in the past decades are synthetically produced components attached to the concrete by an epoxy resin matrix [1-5]. These materials are known as Fiber Reinforced Plastics (FRP). FRPs are carbon, glass, aramid or basalt fibers in a polymer matrix. The latest introduction by the FRP industry is rods. These FRP rods are light but extremely 
strong, their tensile strength measuring up to $3000 \mathrm{MPa}$ [6-8]. The rods are produced with a diameter of $8 \mathrm{~mm}$ and $10 \mathrm{~mm}$.

The product manual mandates an embedment depth of at least 1.5 of the rod diameter; this depth must be achieved to provide sufficient bond for transferring the tensile strain from the cracked concrete to the rods. In practice, this depth target is frequently difficult to realize, since the minimum concrete cover depth is limited due to the presence of stirrups. Field experiences learned that sometimes a groove with a depth of only the rod diameter; is the maximum that can be accomplished.

The relative position of the FRP rods to the concrete surface influences the failure mechanism and stress concentrations in the surrounding concrete material [9]. This experimental study looked into the effect of FRP rods embedment depth to the shear-bond capacity and failure mode of 8 $\mathrm{mm}$ FRP rods embedded in a $36 \mathrm{MPa}$ cylindrical compression strength concrete.

\section{RESEARCH METHODOLOGY AND EXPERIMENTAL SET-UP}

\section{Test set up}

The test set up was designed based on the previous tests on FRP sheets [10]. This direct tensile testing method is widely used to investigate the strength and failure mechanism of bond [11-14]. The aim of the research was to determine the ultimate failure load of a symmetrical assemblage of two rods attached to two concrete blocks (Fig. 1).

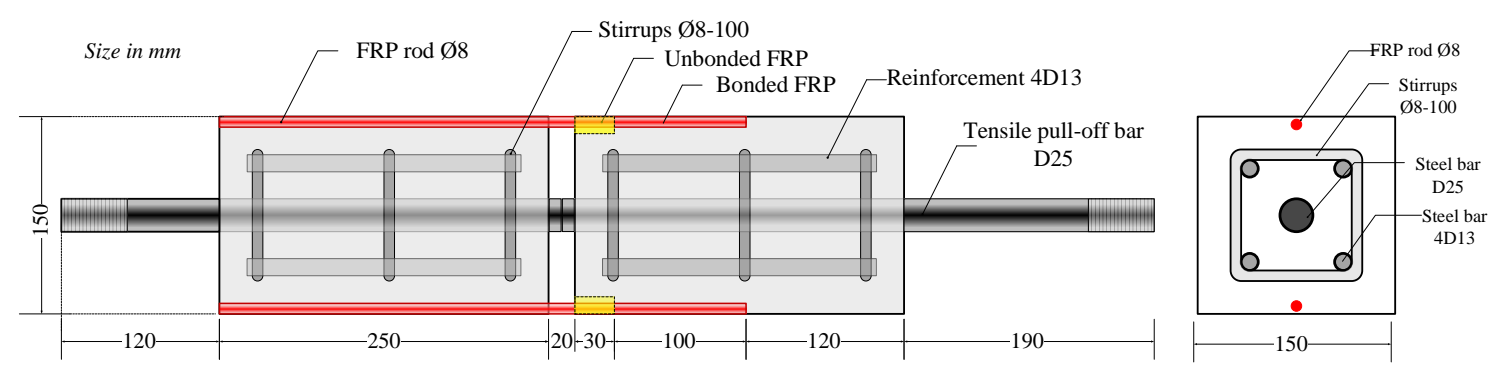

Fig. 1. Experimental test set up for FRP rod bond behavior

Based on the assumption that the bond of FRP rods closely approaches the bond of identical sized steel reinforcing bars, the set-up was designed so that the bonded FRP rod will fail due to bond loss. The designed bond-length was set to $100 \mathrm{~mm}$. To anticipate the high-stress concentration in the edges of the concrete specimens, a plastic tube was used to prevent the unbonded part of the FRP rod, measuring $30 \mathrm{~mm}$, to bond to the concrete. Test results on the effect of FRP rod bond-lengths were conducted by Caro et al. (2017) [15], the bond-length was found to be one of the significant factors influencing the failure mode.

During casting, the tensile pull-off bar with a diameter of $25 \mathrm{~mm}$ was arranged as one solid element. This method would ensure that the test specimen is stable, and the applied tensile force was centric (Fig 2a and Fig 2b). When the grips of the universal testing machine (UTM) were securely set, the pull-off bar was cut, and precision instruments were placed (fig 2c). The UTM applied a centric tensile load to the $25 \mathrm{~mm}$ bars; the increment load was set at $20 \mathrm{~N} / \mathrm{sec}$. The bonded FRS rods were closely observed during the monotonic increment loading. 


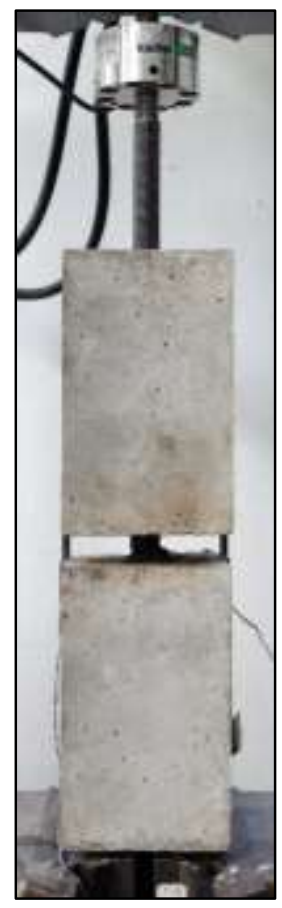

a. Set up

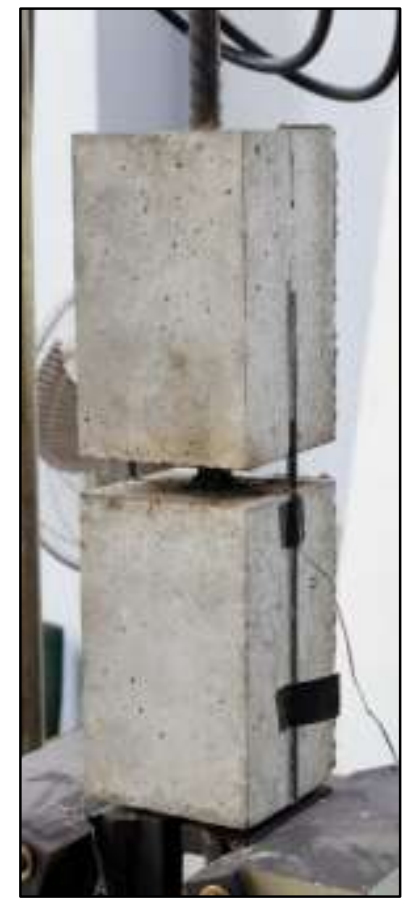

b. FPR rod

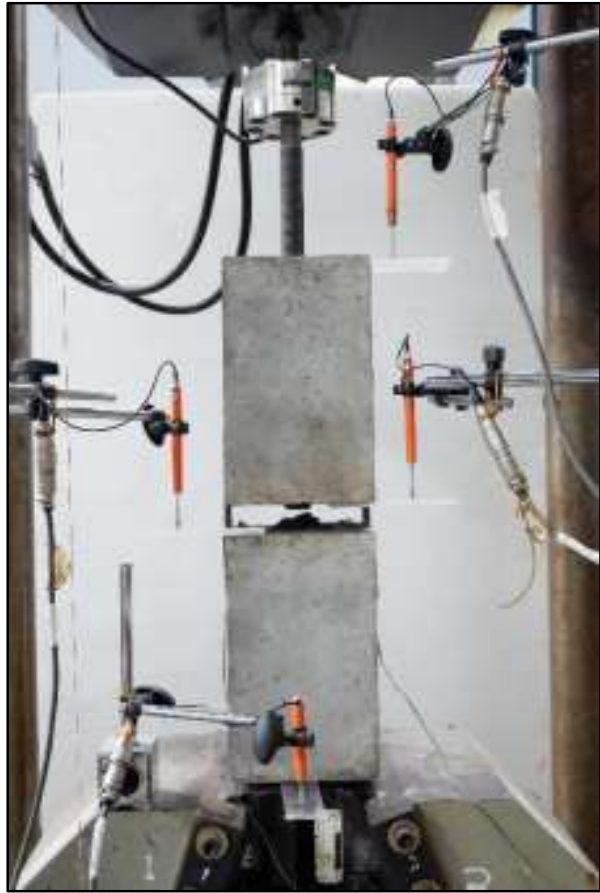

c. Cutting of pull-off bar

Fig. 2. Assemblage and pull-off bar cutting

\section{FRP rod configurations}

The embedded depth of the rods influences the bond between the rod and the epoxy resin, and the epoxy resin to the concrete. The relative position of the rods to the concrete surface also affects the stress distribution in the concrete. The larger stresses are induced near the end of the rod, as a result of an accumulation of strains during the tensile test [16]. The probable failure modes are concrete failure in shear, bond loss in the interface between the concrete and the epoxy, or the failure in the interface between the rod and the epoxy. The failure of the FRP rod in tension was not considered in the experiment since the very high tensile strength of the material. The position of the FRP rods relative to the concrete surface were distinguished into three types (Fig $3 \mathrm{a}, 3 \mathrm{~b}$ and $3 \mathrm{c})$.

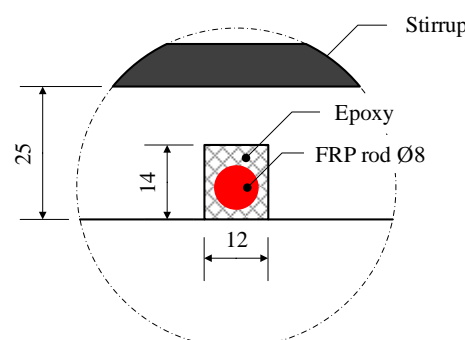

a. $R T F$

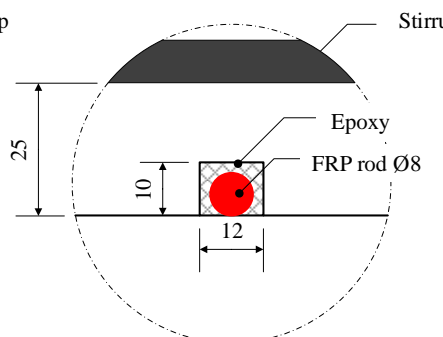

b. RTE

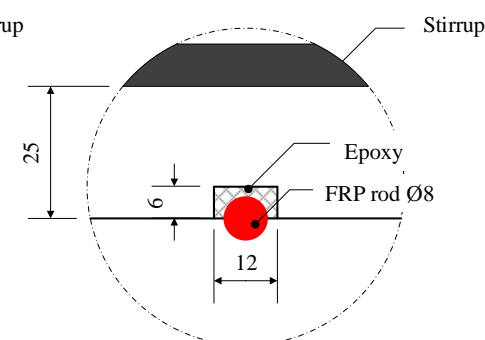

c. $R T H$

Fig. 3. Specimen classification

Specimens RTF that are applied in accordance to the ACI 440 code [17], had an embedded depth of $14 \mathrm{~mm}$. This code mandates a depth of at least 1.5 of the rod diameter. Specimens RTE had a contact area of $75 \%$ with a groove depth of $10 \mathrm{~mm}$ while specimens RTH had an interface of one-half the rod circumference, with a groove measuring $6 \mathrm{~mm}$ in depth. For each category, four (4) specimens were prepared. 


\section{Placement of FRP rods}

The concrete specimens were moist cured for 25 days. A groove was prepared on opposite sides of the concrete block using a diamond, water cooled saw. The block was dried and the groove securely cleaned from all remaining cement debris with a sandblast, and filled with the epoxy (Fig 4a). The position of the rods was carefully monitored to ensure that its arrangement was in accordance to the design (Fig. 4b). Finally, a layer of epoxy was attached to seal the gaps between the rod and the epoxy (Fig. 4c).

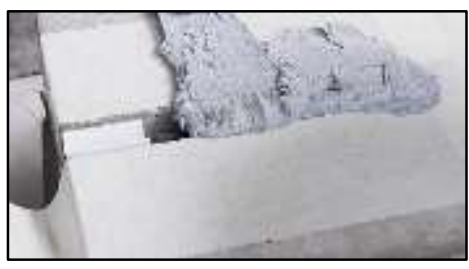

a. Epoxy application

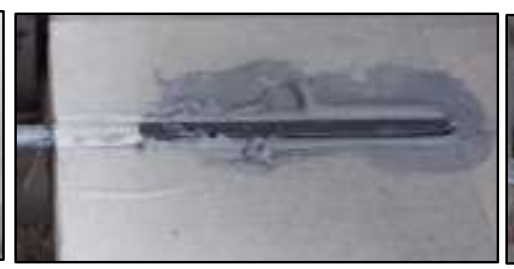

b. rod placement

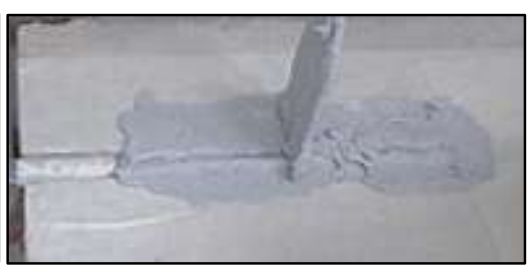

c. finalization

Fig. 4. Rod assembling

The RTH specimen was only filled on both sides of the rod. The attachment of the epoxy to the rod was prevented by covering the half rod with a duct tape (Fig. 5).

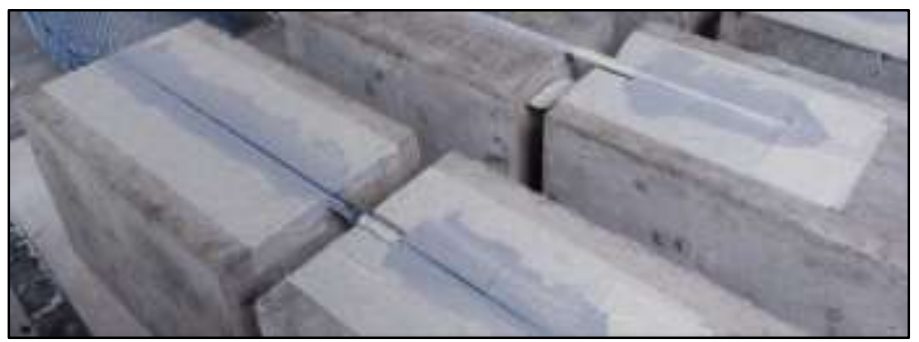

Fig. 5. RTH assemblage

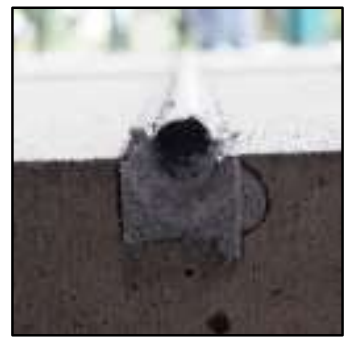

\section{RESULTS AND ANALYSIS}

\section{RTH specimen failure mechanism and strength}

The specimen type RTH had an embedment depth of $6 \mathrm{~mm}$. The specimens' failure modes were distinguished by bond failure between the rod and the epoxy, and concrete failure. No eccentrical loading was observed during the process, and all the specimens failed in the shorter part of the attached FRP rod. Table 1 shows the recorded loads at ultimate and the stress in the corresponding failure area. The interface area between the rod and the epoxy was taken as $\mathrm{A}=\pi r l$ $[11,13]$, were $r$ is the rod radius equal $4 \mathrm{~mm}$, and $l$ is the bond length of the bonded rod measuring $100 \mathrm{~mm}$. As for the concrete failure, the angle of fracture was measured to be approximately $23^{\circ}$. The failure surface was taken as a half cone with a height of $l+30$. 
Table 1. Failure load and stresses for specimens RTH

\begin{tabular}{cccc}
\hline $\begin{array}{c}\text { Specimen } \\
\text { Code }\end{array}$ & $\begin{array}{c}\text { Ultimate load } \\
(\mathbf{k N})\end{array}$ & $\begin{array}{c}\text { Bond stress } \boldsymbol{\tau} \\
(\mathbf{M P a})\end{array}$ & Mode of failure \\
\hline $\mathrm{RTH}_{1}$ & 22.5 & 2.3 & Concrete in shear-bond \\
\hline $\mathrm{RTH}_{2}$ & 22.0 & 17.5 & $\begin{array}{c}\text { Failure in the rod-to-epoxy } \\
\text { interface }\end{array}$ \\
\hline $\mathrm{RTH}_{3}$ & 21.6 & 2.4 & Concrete in shear-bond \\
\hline $\mathrm{RTH}_{4}$ & 21.3 & 16.1 & $\begin{array}{c}\text { Failure in the rod-to-epoxy } \\
\text { interface }\end{array}$ \\
\hline
\end{tabular}

Specimens $\mathrm{RTH}_{1}$ and $\mathrm{RTH}_{3}$ failed due to concrete fracture in shear, as can be seen in Fig 6. The stress in the concrete at failure was calculated to be $2.4 \mathrm{MPa}$, this could be assumed being the shear strength of the concrete at fracture.
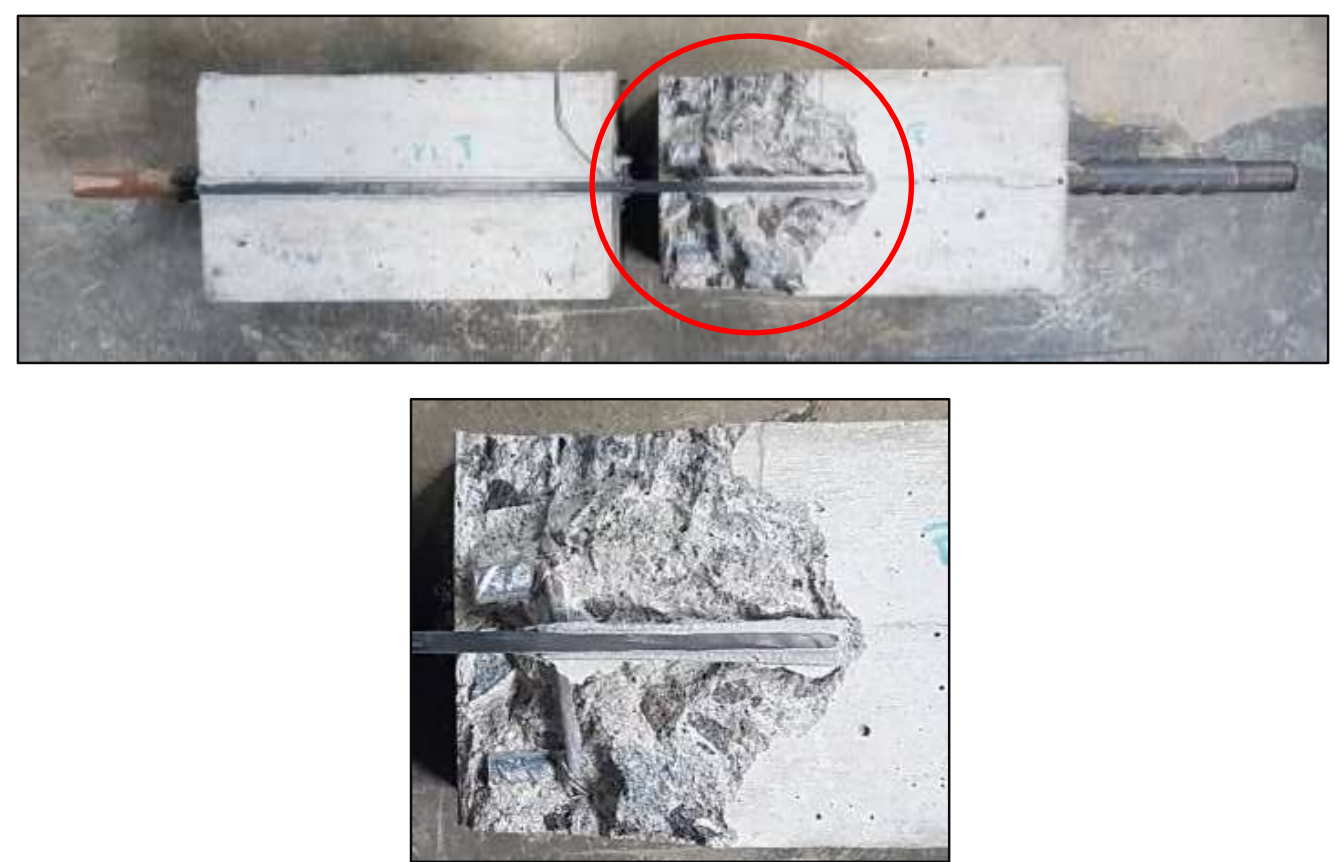

Fig. 6. Concrete failure in specimens RTH

Specimens $\mathrm{RTH}_{2}$ and $\mathrm{RTH}_{4}$ failed due to bond loss in the interface between the rod and the epoxy. The very limited contact area of only one-half of the rod, drastically increased the stresses in the interface. As seen in Fig. 7, at failure the stresses in this area measured up to $16 \mathrm{MPa}$ (Fig. 7). The bond between the epoxy and concrete, however remained intact.

The findings underlined the research work of Barbieri et al. (2016) [14] conduction pull-off tests on a variation in size and shapes of FRP reinforcements in direct tension. 

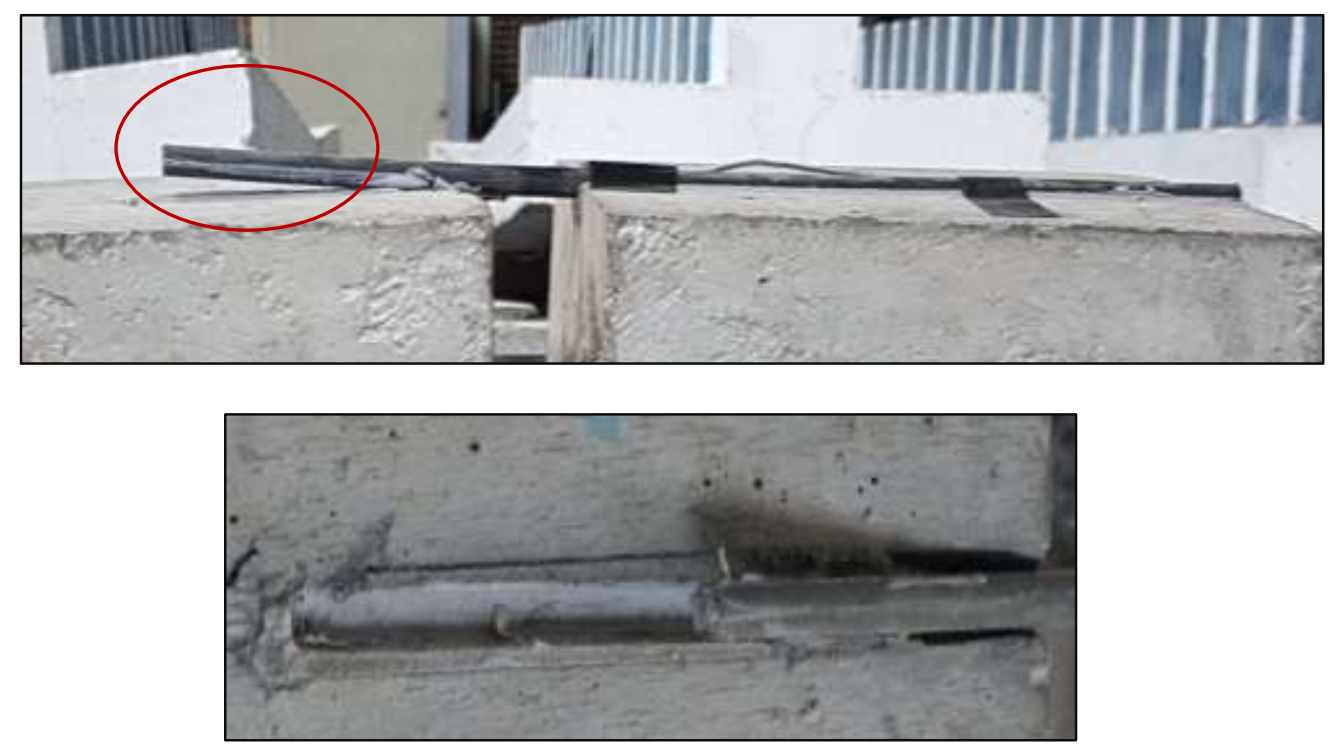

Fig. 7. ITZ bond loss in specimens RTH

\section{RTE specimen failure mechanism and strength}

All RTE specimens failed in the concrete area adjacent to the rod. Table 2 represents the results.

Table 2. Failure load and stresses for specimens RTE

\begin{tabular}{cccc}
\hline $\begin{array}{c}\text { Specimen } \\
\text { Code }\end{array}$ & $\begin{array}{c}\text { Ultimate load } \\
(\mathbf{k N})\end{array}$ & $\begin{array}{c}\text { Bond stress } \boldsymbol{\tau} \\
(\mathbf{M P a})\end{array}$ & Mode of failure \\
\hline $\mathrm{RTE}_{1}$ & 26.8 & 2.7 & Concrete in shear-bond \\
\hline $\mathrm{RTE}_{2}$ & 26.1 & 2.7 & Concrete in shear-bond \\
\hline $\mathrm{RTE}_{3}$ & 24.7 & 2.6 & Concrete in shear-bond \\
\hline $\mathrm{RTE}_{4}$ & 26.1 & 2.7 & Concrete in shear-bond \\
\hline
\end{tabular}

It was observed that the bond stresses at failure were slightly higher when compared to the RTH specimens, resulting in an average shear strength of $2.7 \mathrm{MPa}$ at failure. This $15 \%$ increase is due to the fracture plane that moved inwards, to the concrete block. It is suggested that in the center of the block, a denser concrete is present. Another explanation is that the rise in strength is due to the effect of the Poisson ratio, and a confinement strain in the direction perpendicular to the load strains was created [15].

\section{RTF specimen failure mechanism and strength}

The failure mode of all RTF specimens was identical to the RTE specimens. The failure was unmistakable in the concrete area. Underlining the previous conclusion on the increase in bond strength upon fracture, it was also shown that the shear strength at failure was slightly higher when compared to the RTE specimens. The average shear strength was calculated as $2.8 \mathrm{MPa}$. Table 3 represents the results. 
Table 3. Failure load and stresses for specimens RTF

\begin{tabular}{cccc}
\hline $\begin{array}{c}\text { Specimen } \\
\text { Code }\end{array}$ & $\begin{array}{c}\text { Ultimate load } \\
(\mathbf{k N})\end{array}$ & $\begin{array}{c}\text { Bond stress } \boldsymbol{\tau} \\
(\mathbf{M P a})\end{array}$ & Mode of failure \\
\hline $\mathrm{RTF}_{1}$ & 28.2 & 2.7 & Concrete in shear-bond \\
\hline $\mathrm{RTF}_{2}$ & 29.6 & 2.8 & Concrete in shear-bond \\
\hline $\mathrm{RTF}_{3}$ & 31.1 & 2.8 & Concrete in shear-bond \\
\hline $\mathrm{RTF}_{4}$ & 30.1 & 2.8 & Concrete in shear-bond \\
\hline
\end{tabular}

The shifting from the edge position of the rod to the center of the groove didn't significantly increase the shear strength. Fig. 8 represents the failure pattern of both RTE and RTF.

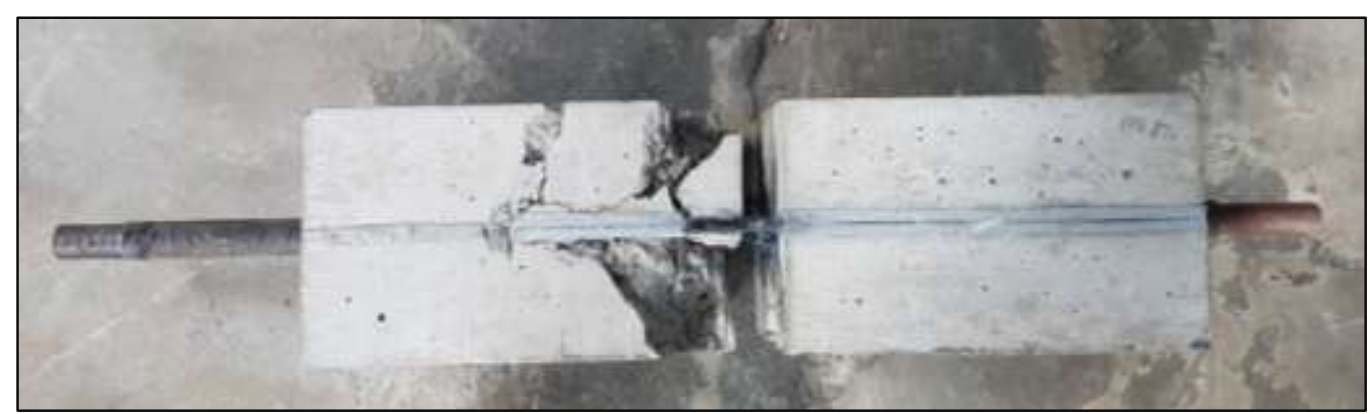

Fig 8. Concrete failure pattern of RTE and RTF

Fig. 9 graphically represents the stresses at failure for all three categories. The specimens that failed in the ITZ bond have a very high stress level due to the small area of the interface.

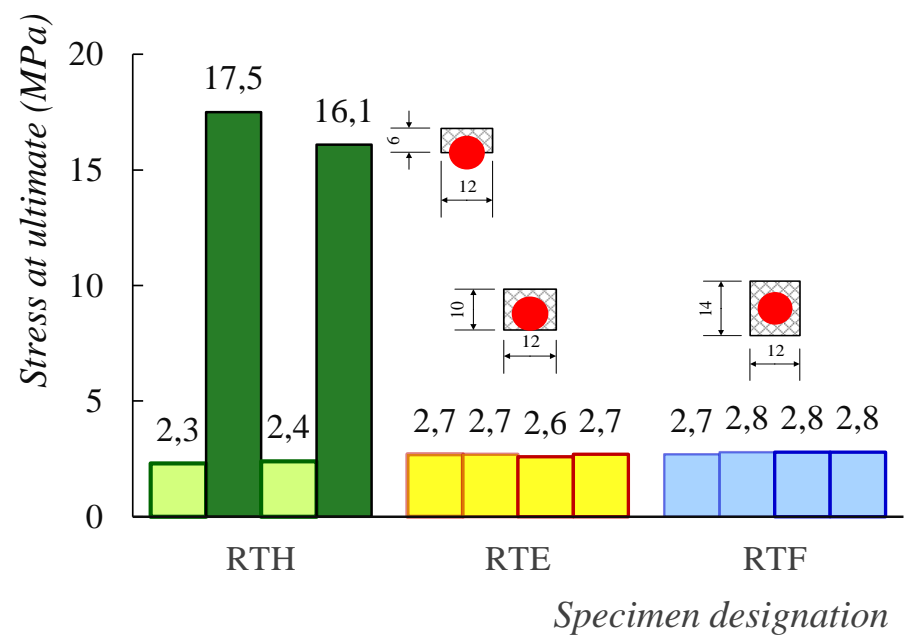

Fig 9. Failure stresses comparison

To evaluate the effect of embedment depth to the stresses in the concrete at failure, the average strengths were plotted against the embedment-to-rod diameter ratio, as can be seen in Fig. 10. 


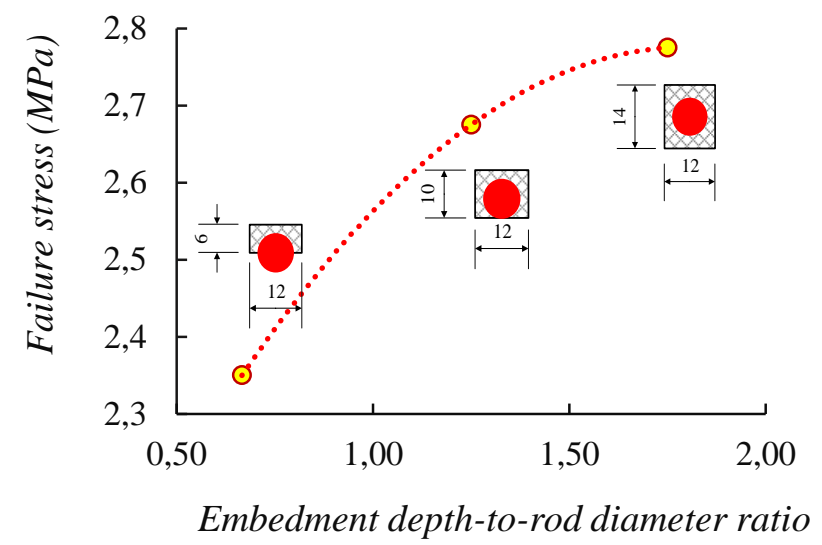

Fig 10. Rate of stress increase as a function of embedded rod depth

The increase rate followed a parabolic, convex path, suggesting that a convergent state exist. The increase is more pronounced when the rod's position is shifted from the outer concrete layers when compared to the arrangement inside the concrete itself. This result suggested that placing the rod deviating from the codes could still provide a good bond, and the assembling of these rods could be optimized.

\section{CONCLUSION}

The embedment depth of $8 \mathrm{~mm}$ FRP rods significantly affects the failure mechanism of concrete. The rods that are attached on the surface with only one half of its surface area attached to the concrete through the epoxy resin, very likely will fail in debonding of the interface between the rod and the epoxy. The test results suggested, however that $50 \%$ of all specimens in this category showed concrete failure. When applying the rod near the surface, a very thorough and accurate application is required. The bond strength of the interface between the rod and the epoxy was approximately 16 to $17 \mathrm{MPa}$.

All full embedded rods, including the type where the rod was placed parallel the concrete surface, resulted in concrete shear failure. The stresses at ultimate increased, as a function of embedment depth, suggesting that the thicker the concrete cover, the higher the shear strength of concrete becomes. This enhancement is most probably originated from the better density of the concrete, farther away from the surface layers, and the strain in the direction perpendicular to the load-strain, resulting in confinement in compression.

The application of the groove and epoxy is crucial to the effectiveness and final result, the bond between the epoxy and the concrete is on average much higher than the bod in the interface of the rod adjacent to the resin. The test was conducted with plain rods, a deformed shape would result in a larger bond area, and most probably yield in the failure of concrete, even for a half embedded rod.

\section{REFERENCES}

[1] Wu, Y., Zhou, Z., Yang, Q., Chen, W., (2010), On shear bond strength of FRP-concrete structures, Engineering Structures, Volume 32, 897-905.

[2] Lesmana, C., Hu, H.-T., Lin, F.-M. and Huang, N.-M., (2013), Numerical analysis of square reinforced concrete plates strengthened by fiber-reinforced plastics with various patterns, Composites Part B: Engineering, Volume 55, 247-262. 
[3] Razaqpur, A. G. and Saverio Spadea, S., (2015), Shear strength of FRP reinforced concrete members with stirrups, Journal of Composites for Construction, Volume 19, 04014025.

[4] Osman, B. H., Wu, E., Ji, B. and Abdulhameed, S. S., (2017), Repair of Pre-cracked reinforced concrete (RC) beams with openings strengthened using FRP sheets under sustained load, International Journal of Concrete Structures and Materials, Volume 11, 171-183.

[5] Fu, B., Teng, J. G., Chen, G. M., Chen, J. F., Guo, Y.C., (2018), Effect of load distribution on IC debonding in FRP-strengthened RC beams: Full-scale experiments, Composite Structures, Volume $188,483-496$.

[6] Gicquel, Y., Hamelin, P., Ferrier, E., (2006). Test report Laboratoire Mécanique Matériaux et Structures. No. SIKA/06/01 du 04/05/06, Universite Lyon I, France.

[7] Al-mahmou, F., Castel, A., Francois, R., Christian Tourneur, C., (2007), Effect of surface preconditioning on bond of carbon fibre reinforced polymer rods to concrete, Cement and Concrete Composites, Volume 29, 677-689.

[8] Product data sheet Sika Carbodur BC rods dan SikaWrap 231 C, (2017).

[9] Veljkovic, A., Carvelli, V., Haffke, M. M. and Pahn, M., (2017), Concrete cover effect on the bond of GFRP bar and concrete under static loading, Composites Part B., Volume 124, 40-53.

[10] Tudjono, S., Han, A. L., Hidayat, A., Purwanto, (2017). Experimental Study on the Concrete Surface Preparation Influence to the Tensile and Shear Bond Strength of Synthetic Wraps. Procedia Engineering, Volume 171, 1116-1122.

[11] Baena M., Torres, L., Turon, A. and Barris, C., (2009). Experimental study of bond behavior between concrete and FRP bars using pull-out test. Composites: Bart B, Volume 40, 784-797.

[12] Aghlara, R., Abdullah, R. and Tahir, M. M., (2012). Mapping full-field bond stress distribution on concrete using digital image correlations. Journal of Applied Science, Volume 12(21), 2235-2243.

[13] Capozucca, R, (2013), Analysis of bond-slip effects in RC beams strengthen with NSM CFRP rods, Composite Structures, Volume 102, 110-123.

[14] Barbieri, G., Biolzi, L., Bocciarelli, M. and Cattaneo, S., (2016), Size and shape effect in the pull-out of FRP reinforcement from concrete, Composite Structures Volume 143, 395-417.

[15] Caro, M., Jemaa, Y., Dirar, S. and Quinn, A., (2017), Bond performance of deep embedment FRP bars epoxy-bonded into concrete, Engineering Structures, Volume 147, 448-457.

[16] Biolzi, L., Ghittoni, C., Fedele, R and Rosati, G., (2013), Experimental and theoretical issues in FRPconcrete bonding, Construction and Building Materials, Volume 41, 182-190.

[17] ACI 440.2R-08, (2008). Guide for the Design and Construction of Externally Bonded FRP Systems for Strengthening Concrete Structures. American Concrete Institute, Farmington Hills. 